\title{
Do silêncio como via longa. Contribuição para uma pedagogia do silêncio
}

\author{
Alberto Filipe Araújo
}

Resumo:

Tratamos no presente artigo de um tema relativamente estranho à tradição filosófico e educacional portuguesa, ainda que o mesmo tenha ultimamente merecido alguma atenção por parte das publicações religiosas e da espiritualidade em geral no nosso país. Neste contexto, defendemos que a vivência e a prática do silêncio é uma das condições para se meditar criativamente em ordem à elaboração de um conhecimento iniciático e pedagógico conforme uma Bildung que faça de cada um Mestre de si-mesmo. Dedicamos a primeira parte ao tema do "silêncio como via longa" enfatizando a importância de procurar-se não só o silêncio interior, como também nele viver em ordem à meditação criativa e respeitadora da Tradição. Na segunda parte tratamos da pedagogia do silêncio como um tipo de pedagogia que procura ensinar aquele que se interessa pelo silêncio interior com o objetivo não somente de ele ser o cadinho onde um pensamento ressonante germinará, como também desse mesmo silêncio poder contribuir, impelido por uma espécie de libido educandi, para trans-formar (Umbildung) um sujeito devoto de um silêncio interior que, por sua vez, o faça melhor compreender a palavra que pensa e que diz. Trata-se de uma pedagogia do silêncio que, ao contribuir quer para uma iniciação ao silêncio, quer para a gestação de uma Palavra, se afirme consonante com uma espécie de paideia de um silêncio interior instigador da Palavra justa.

Palavras-chave:

silêncio interior; via longa; pedagogia; iniciação; palavra. 


\title{
On Silence as a Long Way. A Contribution to the Pedagogy of Silence
}

\begin{abstract}
We have dealt in this article with a theme relatively foreign to portuguese philosophical and educational tradition, although it has lately deserved some attention from religious and spiritual publications. Within this context, we have contended that the experience and practice of silence is one of the conditions for creative meditation in order to develop an initiatory and pedagogical knowledge according to a Bildung that makes each Master of himself. We have dedicated the first part of the paper to the theme of "silence as a long way" emphasizing the importance of seeking not only interior silence but also living in it towards the creative and respectful meditation of the Tradition. In the second part of the article we have dealt with the pedagogy of silence as a type of pedagogy that seeks to teach those who are interested in inner silence with the objective not only of being the crucible where a resonant thought will germinate, but also of the same silence, impelled by a kind of libido educandi, to transform (Umbildung) a devotee of the inner silence that, in turn, makes one better understand the word one thinks and says. It is a pedagogy of silence which, by contributing either to an initiation into silence or to the gestation of a Word, may be consonant with a sort of paideia of an interior silence that instigates the Fair Word.
\end{abstract}

Keywords: inner silence; long way; pedagogy; initiation; word.

\section{Du Silence comme une Longue Voie. Contribution pour une Pédagogie du Silence}

Résumé : Dans cet article nous traitons un thème relativement étranger à la tradition philosophique et éducationnelle portugaise, bien qu'il ait récemment mérité une certaine attention de la part des publications religieuses et de la spiritualité en général dans notre pays. Dans ce contexte, nous soutenons que l'expérience vécue et pratique du silence est l'une des conditions pour méditer de manière créative afin qu'on puisse développer une connaissance initiatique et pédagogique selon un Bildung qui fait de chaque Maître l'auteur de lui-même. Nous consacrons la première partie au thème du "silence comme une longue voie» en soulignant l'importance de rechercher non seulement le silence intérieur, mais aussi comment vivre afin de mener à bien une méditation créative et respectueuse de la Tradition. Dans la deuxième partie, nous abordons la pédagogie du silence comme une sorte de pédagogie qui cherche à enseigner à celui qui s'intéresse au silence intérieur avec l'objectif de contribuer, poussé par une sorte de libido educandi, à trans-former (Umbildung) un sujet qui se dédie au silence intérieur en lui permettant de mieux comprendre la parole qu'il pense et qu'il dit source d'une pensée réonnante. II s'agit d'une pédagogie du silence qui, en contribuant aussi bien à une initiation au silence, qu'à la gestation d'un mot, est en accord avec une sorte de paideia du silence intérieur instigateur de la Parole juste.

Mots clés : silence intérieur ; via longa ; pédagogie ; initiation ; parole.

\section{Del Silencio como Vía Larga. Contribución a una Pedagogía del Silencio}

Resumen: Nos ocupamos en este artículo de un tema relativamente extraño a la tradición filosofica y educativa portuguesa, si bien últimamente dicho tema ha ganado algo de atención en las publicaciones religiosas y de espiritualidad en general en nuestro país. En este contexto, defendemos que el tema del silencio es una de las condiciones para meditar creativamente en orden a la elaboración de un conocimiento iniciático y pedagógico conforme a una Bildung que haga de cada uno un Maestro de sí mismo. Dedicaremos la primera parte de este artículo al tema del "silencio como vía larga", enfatizando la importancia no solo de la búsqueda del silencio interior, sino también de cómo vivirlo, de cara a una meditación creativa y respetuosa con la Tradición. En nuestra segunda parte trataremos de la pedagogía del silencio como un tipo de pedagogía que busca enseñar a aquél que se interesa por el silencio interior con el objetivo no solo de que sea el crisol en el que pueda germinar un pensamiento resonante, sino también de que ese mismo silencio pueda contribuir, impelido por una especie de libido educandi, a trans-formar (Umbildung) al sujeto que lo practica, para que pueda comprender mejor las palabras que piensa y que dice. Se trataría de una pedagogía del silencio que, al contribuir tanto en la iniciación en el silencio, como en la gestación de una Palabra, se afirme consonante con una especie de paideia de un silencio interior instigador de la Palabra justa.

Palabras clave: silencio interior; vía larga; iniciación; palabra. 
"Sem as amarras do silêncio, a vida é um movimento deprimente, uma pequena barca frágil incessantemente batida pela violência das correntes. O silêncio é o muro exterior que devemos erguer para proteger o edifício interior".

Robert Sarah \& Nicolas Diat (2017).

A Força do Silêncio, p. 7.

\section{Introdução}

O presente artigo ${ }^{1}$ admite que as discussões sobre a educação de um modo geral negligenciaram o papel que o silêncio desempenha na aprendizagem e na própria formação (Bildung) do sujeito, mas não trata explicitamente do tema do silêncio e do seu lugar na educação (Caranfa, 2004: 211-230, 2006: 85-103; Forrest, 2013: 605-622; Lees, 2012; Zembylas, 2004: 193-210). É antes uma reflexão situada numa espécie de um entre-dois: a meio caminho da Filosofia existencial e da Filosofia da Educação, e preconiza que compete a uma pedagogia do silêncio conduzir o sujeito, mediante o exercício do silêncio interior, à meditação, ou seja, ao pensamento reflexivo radical, e mesmo, seria já um ideal, à própria contemplação. Pressupõe, assim, que uma das condições necessárias e fundamentais do ato de pensar é a qualidade do silêncio interior em cada um de nós, ainda que outras condições sejam igualmente necessárias, tais como: a qualidade do silêncio exterior, a importância do retiro espiritual, a motivação psicológica e a força ontológica do sujeito impelido para habitar as pregas do pensamento, a pregnância dos temas estudados, a sua fé ou a ausência dela, o seu apelo, ou não, à mestria, a sua capacidade de escutar, enfim, as suas qualidades morais e sapienciais (paciência, disciplina, humildade, misericórdia, sentido do perdão...), etc.

É por isso que na primeira parte do nosso artigo tratamos do "silêncio como via longa" enfatizando a sua dimensão interior na linha do silêncio vivido pelas Ordens religiosas de recolhimento de estrita observância (Merton, 1953, 1960; MacCulloch, 2013). Por outras palavras, o silêncio que nos importa é aquele de tipo espiritual, ontológico no sentido que Ihe dão Max Picard (1954), Joseph Rassam (1980) e Bernard Dauenhauer (1980), e não tanto o "silêncio psicolinguístico", o "silêncio interactivo" e o "silêncio sociocultural" (Bruneau, 1973: 17-46) que são objeto de estudo no quadro da Retórica, das Ciências da Comunicação, da Linguística (particularmente da Pragmática e da Semântica), da Literatura, entre outras disciplinas. Na segunda parte tratamos de uma pedagogia do silêncio preocupada em dar uma orientação filosófico-educacional ao silêncio interior pela simples razão de que este não se basta por si sem estar guiado por um conjunto de finalidades sejam elas espirituais, filosóficas, educacionais, retórico-linguísticas e comunicacionais, psicológicas, etc. Por fim, concluímos que 
esta posição, que privilegia o silêncio interior e uma pedagogia que the seja adequada não se opõe à Palavra desde que esta seja justa, pregnante de sentido e emergente do silêncio interior que deve ser de caráter reflexivo. Aliás, silêncio e palavra são as duas faces da mesma moeda. O silêncio por si só não tem um valor absoluto, assim como uma palavra, ainda que corretamente proferida, não é necessariamente de oiro. Há silêncios inautênticos e palavras também.

O objectivo do estudo é contribuir para que o tema do silêncio não só seja melhor compreendido, como também que a sua presença se estenda da alta espiritualidade, da abordagem filosófica para a educação em geral e, particularmente, que muito influencie a reflexão filosófica sobre a educação.

\section{Do Silêncio como via longa}

Evocar o silêncio interior (Baldini, 1986: 84-91), denso, convocador, suscitador de uma palavra reflexiva, meditativa e contemplativa implica, ou pressupõe necessariamente, uma iniciação ao silêncio (o chamado voto de silêncio) do tipo que os noviços das ordens religiosas contemplativas são obrigados a respeitar se procuram aceder ao estádio de iniciado - o de monge consagrado. Aqueles que nelas entram, iniciam-se normalmente como estagiários, passam a postulantes, fazem o noviciado e, depois de alguns anos, são admitidos em caráter definitivo. Especialmente desde o estádio do noviciado os noviços são iniciados na disciplina do silêncio reflexivo, interior que convoca os afluentes do próprio silêncio, lembrando aqui um dos títulos de Eugénio de Andrade, em ordem à meditação e vita contemplativa. Um longo caminho lento de aprendizagem a escutar-se a si-mesmo como um exercício paciente de olhar o Outro, de acolhê-lo de forma hospitaleira: escutar o próximo não já como um estranho sem rosto, mas antes como um rosto iluminante do meu. No fundo, encontramos aqui o tema da iniciação, tão caro a Mircea Eliade, em que tão-somente retemos o motivo da morte iniciática por ser um dos traços mais marcantes do referido tema: "A morte iniciática é portanto um recomeço, ela não é nunca um fim” (Eliade, 2008: 274). Numa palavra, pela morte iniciática (de que a entrada no espaço de clausura é exemplo), que the causa sofrimento, o neófito sofre um processo de regeneração espiritual, ressuscitando já como monge, a categoria de iniciado que já comunga da sabedoria e da ciência "verdadeira" transmitidas pela tradição religiosa, mística e simbólica da sua comunidade:

Convém nunca esquecer que a morte iniciática significa simultaneamente o fim do homem 'natural', não cultural - e a passagem a uma nova modalidade de existência. A de um ser 'nascido para o espírito', ou seja que não vive unicamente numa realidade 'imediata'. A morte iniciática faz, portanto, parte integrante 
do processo místico pelo qual um se torna outro, modelado a partir do modelo revelado pelos deuses ou pelos antepassados míticos. O que equivale a dizer que só se torna homem verdadeiro na medida em que se deixa de ser um homem 'natural' e se assemelha a um Ser sobrehumano (Eliade, 2001: 276).

$\mathrm{Na}$ verdade, a morte iniciática afirma-se como a condição sine qua non de toda a regeneração espiritual e, em última instância, assegura a sobrevivência da alma e mesmo da imortalidade. À luz dos ritos iniciáticos esta valorização religiosa da morte ritual, que consiste na vitória sobre o medo da morte real e na crença na possibilidade de uma sobrevivência espiritual do ser humano, revela-se um dos ensinamentos a reter e a pensar num mundo des-sacralizado que esqueceu o poder salvífico da iniciação de tipo tradicional. E um dos modos de restaurar-se um mundo mais espiritual, mais sacralizado, mais convivial é precisamente através do silêncio interior por contraposição ao silêncio exterior ou epidérmico.:

Em definitivo, silêncio epidérmico e silêncio interior são duas faces opostas e diametralmente distanciadas. Estão unidas de forma aparente, porque ambas têm a mesma presença exterior, mas os significados de uma e outra são distintos. Um é casual e empobrecedor, o outro é intencional e abre ao sujeito uma realidade nova, completamente diferente, abre-o ao mistério mais íntimo de si mesmo, da realidade e da existência (Torralba Roselló, 2001: 112).

Assim, aquele silêncio que nos importa é o de natureza mais ontológica, mais espiritual, mais denso ontologicamente numa perspetiva de tipo essencialista (Dauenhauer, 1980). Esta proposta de silêncio afasta-se da perspetiva funcionalista dos "estudos da comunicaçao, da semântica, da linguística da semiótica" e das "perspetivas sociais e pragmáticas” (Bruneau, 1973: 17-46; Jaworski, 1993: 28-97, 1997).

Não significa, contudo, que na espessura e densidade de uma via longa do silêncio, em ordem à meditação e à contemplação (Painadath, 2015: 703-714)2, as formas de silêncio citadas por Bruneau e por Jaworski não estejam de algum modo presentes. Sim, estão, não como fins em si, antes como meios ou estádios a percorrer nessa mesma via longa. Assim, também na perspetiva destes autores, Vernon Jensen aponta cinco funções próprias do silêncio: "a) uma função de ligação; b) uma função de afectação/comovedora; c) uma função revelacional, d) uma função ajuizadora, e) uma função ativadora" (1973: 249). A nossa intenção não é examinar o funcionamento do silêncio em certos contextos como aqueles que Richard Johannesen indica: "(1) $O$ seu papel nos processos humanos e no desenvolvimento cultural; (2) o seu papel na comunicação interpessoal intencional e quotidiana; (3) o seu papel na vida política e cívica; e (4) o seu papel em contextos patológicos, tais como o de aconselhamento 
e da psicoterapia (1974: 25). Também não é nossa intenção estudar, ainda que reconheçamos a sua importância, a relação que sempre poderá ser estabelecida entre "retórica e silêncio", como faz Robert Scott (1972: 146-158). Com isto não queremos dizer que estes e outros estudos citados, como os de Dennis Kurzon $(2007,1998)$, não sejam pertinentes para compreendermos melhor e de modo mais aprofundado a natureza e a tipologia do silêncio, nomeadamente na interação social. Resumindo Bruneau (1973), Jensen (1973) e Johannesen (1974), Kurzon distingue quatro tipos de silêncio presentes na interação social: o "silêncio conversional", "silêncio temático", o "silêncio textual" e o "silêncio situacional" (2007: 1676-1681). Destes tipos de silêncios merece a nossa atenção o chamado "silêncio textual" (2007: 1679), presente na meditação que recorre, pela sua própria natureza, à leitura em silêncio ou mesmo à sua récita em alta voz já num contexto determinado, nomeadamente religioso.

Os vários tipos de silêncio apontados revelam-se pertinentes no domínio da psicolinguística, da comunicação, da pragmática, da análise do discurso, etc., e não os podemos esquecer no presente estudo, ressaltando ainda, no grupo dos "silêncios individuais" enumerados por Muriel Saville-Troike (1985: 3-18), o tipo de silêncio não-interativo que engloba o silêncio contemplativo e o silêncio meditativo. Estes, na verdade, são os dois tipos de silêncio que privilegiamos na dimensão filosófica, ontológica, do silêncio, com todas as implicações que deles decorrem, porquanto essas modalidades de silêncios, pela sua natureza, inscrevem-se numa perspetiva de caráter filosófico e educacional no sentido que ela assume no contexto da Bildung germânica (Gennari, 2005; Sola, 2003). Daí que uma iniciação e uma sensibilização para encontrar o silêncio interior se imponha como uma das tarefas mais urgentes que deve ser considerada e ponderada por aquilo que Wilhelm Dilthey designou por "Ciências do Espírito" (Geisteswissenschaften) (1970). Enfim, importa, na verdade, uma iniciação ao silêncio que não deve ser confundida com uma iniciação à arte de escutar por mais que esta seja relevante e necessária. O silêncio interior que nos ocupa inspira-se privilegiadamente naquele tipo de espiritualidade conhecida e vivida por certas ordens religiosas como, por exemplo, a "Ordem da Cartuxa", que se dedica muito especialmente à oração e à contemplação, e cujos monges e monjas vivem mergulhados numa solidão voluntária convictos de que Deus se dá e se encontra no e pelo silêncio (Noacco, 2007: 69-72). Trata-se, na verdade, de um silêncio intencional, desejado e trabalhado como que artesanalmente em ordem à realização de uma viagem iniciática no interior do tempo do silêncio. Uma busca iniciática que é o prolegómeno de uma experiência interior anunciadora, assim se espera, de silêncios auspiciosos na tradição da "vida silenciosa" (Merton, 1960).

Deste modo, o silêncio interior aparece-nos para nós como condição de um pensamento reflexivo, crítico e imaginativo em ordem à meditação e contemplação. A meditação impõe-se como estádio superior da reflexão dita profana que identificamos 
com o estudo apurado em torno de determinado tema como, por exemplo, "o tempo do silêncio" como aquele tempo que exige uma entrega devota. O silêncio interior acontece envolvido no silêncio exterior, pela concentração espiritual, porquanto esta é importante para libertar, esvaziar, o pensamento dos muitos murmúrios que o habitam.

O silêncio interior, não nos iludamos, é um estádio de poucos privilegiados, ainda que não o consideremos raro de a ele aceder. Ele é, na verdade, a condição para que cada um possa pensar e recolher-se de modo a calar o burburinho desgastante que caracteriza o nosso pensamento e vida ativos, enfim os pensamentos barulhentos que em permanência afluem à consciência. Para que tal aconteça é necessário praticar a meditação, não necessariamente na linha dos Padres do deserto e dos místicos (Teresa de Ávila por exemplo), mas na linha do yoga e do zen, para se atingir mediante o silêncio a calma interior: "Conquista difícil, o silêncio permanece inacessível ao espírito que queria reduzi-lo a um fim, enquanto ele é a via. (...) O silêncio interior é, portanto, mais que um fim, um meio que conduz à elevação" (Noacco, 2017: 76). Uma elevação que bem poderia ser sinónimo da contemplação, da transformação e mesmo da purificação: o silêncio comunicativo como fonte de ascensão da alma como possibilidade de uma mistagogia (Mendonça, 2012: 215-216).

O desafio que se coloca é como fazer surgir o silêncio interior e vivê-lo com sentido da trans-formação (Umbildung, Sola, 2003). Esta modalidade de silêncio não é uma mera dádiva, mas antes um dom que carece de um trabalho árduo caraterizado por esmorecimento, sobressaltos, angústia, e desespero. É o caminho das pedras, ou do deserto, para aquele que aceita seguir esta via iniciática, pois é disso que realmente se trata e não de um mero exercício intelectual e erudito por mais meritório que ele o seja. Pelo silêncio interior a nossa alma predispõe-se ao leque dos silêncios que se encontram na natureza, no universo, na vida e, muito especialmente, teima em afinar o ouvido para escutarmos o silêncio interior que está em nós sem disso o sabermos: Sileo ergo sum ${ }^{3}$.

O silêncio interior é uma força espiritual magnética que deve ser olhada como um dom, como uma vocação que, contudo, não nos é simplesmente dada: é preciso tanto merecê-la, como conquistá-la. A força do silêncio (Sarah; Diat, 2017; Noacco, 2017) em muito nos transcende, mas parece ser aquela que nos religa à essência do Ser, da voz do mundo e da vida. Neste sentido escreve Noacco:

O silêncio é o alfa e o ómega, o começo e o fim; por ele tudo é também realizado porque ele é o verdadeiro traço de união entre tudo aquilo que existe, o mundo material como o mundo espiritual. O silêncio é o código para compreender o mistério do real, um código que é melhor manter secreto e íntimo, a fim que ele ressoe em nós, no sussurro da nossa passagem (2017: 89). 
E assim pode então chegar o momento do recolhimento que é um fazer silêncio, um calar-se em presença do mistério divino, do inefável. É o silêncio que, desde a Antiguidade, está indissoluvelmente ligado ao mundo espiritual, religioso (mistérios, meditação e contemplação) e da alta reflexão profana. Este tipo de reflexão é o pensar em silêncio meditativo que convida todo aquele que o pratica a entrar em diálogo com o seu universo interior em ordem à tessitura de pensamentos transpostos, tantas vezes, para uma escrita iluminada. O despojamento do pensamento de tudo aquilo que Ihe é secundário torna-se crucial para a comunhão com o ser e mesmo para a libertação de uma palavra banhada no silêncio interior que nos orienta para a escuta da nossa interioridade. Esta, por sua vez, é outro modo de perscrutarmos os movimentos complexos e variados da nossa consciência. A este respeito, lembrando que Francesc Torralba Roselló (2001) recenseou dezasseis formas de silêncio, nós defendemos que o silêncio interior é todo aquele que, ao contrário do silêncio exterior, se assume como um ato de liberdade por parte daquele ou daquela que sabe que o necessita para atingir a sua serenidade, condição sem a qual o pensar, nas suas duas formas mais radicais, a meditação e a contemplação, não acontece (Torralba Roselló, 2001: 47-54). Se a pedagogia do silêncio é a condição para assegurar a serenidade tão necessária à meditação e à contemplação, não devemos igualmente esquecer a pedagogia do olhar porquanto toda a vita contemplativa a pressupõe: "Este aprender a olhar constitui o "primeiro ensinamento preliminar para a espiritualidade" (Han, 2012: 53 e 53-60). As pedagogias do olhar e da escuta complementam a pedagogia do silêncio na medida em que não há silêncio interior sem um olhar íntimo que o acompanhe, assim como um olhar penetrante e circunspeto da vida e do mundo, bem como da interioridade de cada um:

A interioridade é antes um momento, aquele em que faz irrupção a questão ontológica: o mistério da presença no mundo, ser aquilo que se é ao longo da nossa história. A interioridade é o momento de retorno sobre si, a suspensão da turbulência do mundo e o mergulho breve ou longo sobre aquilo que funda aquilo que se é como indivíduo. (...) A interioridade não se opõe ao grito estridente porque ela provém originariamente de um estado de espírito. Mas o silêncio aprofunda-a. (...) A interioridade é para mim uma metaforização do mistério da presença no mundo. (...) A interioridade é o lugar de espanto sem repouso de existir e ter consciência, e do debate incessante com o divino, com as inúmeras figuras do divino que tenho dificuldade em reduzir à univocidade de um Deus único. (Breton \& Le Breton, 2009: 89-90, 97).

Uma interioridade forjada pelo sentido de uma vida silenciosa ativa e, por sua vez, por um humanismo integral que se quer educado sob o signo da graça e da comunhão 
com o sagrado (Reboul, 1992). A interioridade situa-se nos confins da linguagem, o que significa na região da indizibilidade que nos confronta inevitavelmente com o ontológico que em nós habita, enquanto espaço de silêncio, sanctum sanctorum, de cada um. E assim, mais uma vez, uma pedagogia do silêncio é germinadora de toda uma meditação nutritiva da alma que tem sede do indizível e do inefável. Trata-se, assim, de uma sede que, pelo menos idealmente, tende a saciar-se na riqueza ontológica do silêncio interior e mesmo da Palavra justa como tipo de palavra iniciática e virtuosa. 0 Homem, pelo facto de ser "zôon lógon échon", animal que tem logos (razão e linguagem), pode em plena consciência servir-se da palavra, por um lado, para manifestar o justo e o injusto e, por outro lado, para fazer silêncio e escutar. Tanto o silêncio interior como a Palavra justa necessitam do manto protetor da solidão voluntária e trabalhada espiritualmente:

a solidão que revela o mundo da existência criativa onde a vita contemplativa e a vita activa estão magnificamente entrelaçadas. Ao escrever, tentamos restaurar o mundo de silêncio por detrás da nossa vida verbal. (...) O artista ou o escritor, segundo Delacroix, deve manter-se solitário, deve trabalhar em silêncio, de modo que ele possa assim caminhar no sentido de expressar o que tem de mais profundo no seu coração (Caranfa, 2006 : 93).

Do exposto, compreende-se que o silêncio seja uma via, ainda que longa, e jamais constitua um fim em si mesmo. Quando ele se constitui e afirma como um fim, deixa de ser testemunho e catalisador para aceder à elevação espiritual que é a condição para que a pessoa silenciosa aprofunde, num tempo e num espaço meditativo, a sua experiência interior e intersubjetiva: silencio interior, pensar, meditar carecem de uma pedagogia do silêncio que desenvolvemos na secção seguinte.

\section{De uma pedagogia do silêncio}

O silêncio interior carece de uma pedagogia adequada que oriente, quer nas suas implicações espirituais, quer na vivência prática, todo aquele, ou aquela, que a este tipo de silêncio se dedique. Esta pedagogia deve ser procurada osmoticamente no próprio silêncio interior e este, por conseguinte, constituirá a base de ensino e de inspiração para que todos aqueles que dela carecem, meditem em profundidade e, por que não, se sintam disponíveis para contemplarem o ser na epifania do rosto do outro. Por outras palavras, o silêncio só ganha na sua profundidade e espessura ontológica, ética, antropologica e simbólica se, mediante uma pedagogia própria, conduzir o sujeito, na sua qualidade de Mestre ou de discípulo, até à meditação e contemplação como dimensões que implicam necessariamente a compreensão e assimilação intensa 
e profunda da arte e da sabedoria de se fazer silêncio interior (Torralba Roselló, 2001: 56-57). Pela pedagogia do silêncio, que tem em elevada conta a trilogia solidão-meditação-contemplação, acercamo-nos de um modo mais radical da nossa interioridade e do Outro que se tornará um Próximo, assim como o mundo da vida e a vida da terra se tornarão menos estranhos. A este sentimento de não estranheza, Hartmut Rosa desginou-o de "ressonância", que é uma qualidade que a sociedade atual deverá reapreender para se relacionar novamente com um mundo que "en-cante" face a um des-encantado e silencioso (2018: 489-499). Este, como bem o diagnostica o autor, foi gradualmente perdendo o seu sentido, tornando-se aos olhos daqueles que com ele se relacionam, ou mesmo o procuram ver, manifestamente ilegível (2018: 483-488). Ainda que Rosa (2018) aponte uma terapia diferente, com Torralba Roselló (2001) pensamos que é necessário, senão mesmo fundamental, inaugurar uma nova relação com o mundo na base de uma "paideia do silêncio", que é o mesmo que dizer que "precisamos de uma iniciação ao silêncio, uma iniciação à arte de escutar" (Mendonça, 2015). Retomando as palavras de Torralba Roselló, salientamos que:

O nosso tempo requer uma paideia do silêncio, pois não é possível compreender o verbo sem ter experiência do silêncio de onde emana o verbo. Não é possível entender $\mathrm{o}$ alcance das palavras sem observar os limites que as delimitam. A experiência demonstra-nos que a hermenêutica do silêncio é múltipla e complexa. Há tantas formas de silêncio! Há tantas semânticas do silêncio! O silêncio possui mil rostos. Estamos, pois, no princípio de um caminho virgem e desconhecido (2001: 24)4.

Para se percorrer o caminho iniciático do silêncio, povoado de provações e exposto a múltiplos desafios e enigmas, é necessária uma pedagogia do silêncio, um tipo de pedagogia que apele à instauração do silêncio interior, chamando a atenção para a importância e o valor do silêncio interior em ordem a que a Palavra se faça de novo ouvir como "poder da palavra" e não como "palavra do poder" (Le Breton, 1999: 16-17), como lugar de diálogo interior e, consequentemente, lugar propício ao diálogo entre silêncio e palavra (1999: 17-19). Uma pedagogia do silêncio que ensine o sujeito a re-aprender a não ter medo do silêncio (Torralba Roselló, 2001: 38-47), a não ter medo de escutar-se, de pensar e de pensar-se, mesmo que o pensamento, como disse Alberto Caeiro no poema "O Guardador de Rebanhos", incomode: "Pensar incomoda como andar à chuva/ Quando o vento cresce e parece que chove mais" (Pessoa, 2014: 20). O silêncio interior causa medo porque de súbito o sujeito confronta-se com a sua nudez plena de demónios, de interrogações e dúvidas sobre o seu ser, sobre o mundo que o rodeia e, principalmente, sobre o seu destino: "Quando alguém vive a experiência silenciosa, encontra-se totalmente despido consigo mesmo, além de todas 
as coisas e de todas as máscaras. Então, o eu aflora com natural espontaneidade e, deste modo, interpela, pergunta, provoca e apresenta desafios" (Torralba Roselló, 2001: 39).

Ainda que reconheçamos um valor incontornável à palavra não a separamos, à semelhança daquilo que faz Max Picard, do silêncio:

A palavra nasce do silêncio de maneira tão natural e tão desapercebida que parece que ela é somente silêncio devolvido, reverso do silêncio. E é também isso que é a palavra: o verso do silêncio, como silêncio é o verso da palavra. (...) A palavra estabelece, assim, uma relação essencial com o essencial” (1954: 8).

É por isso que a educação não deverá tão-somente privilegiar a palavra, por mais importante que ela seja na relação pedagógica, mas que tenha igualmente em conta esse grande Mestre que é o silêncio, aliás de grande préstimo aos chamados Mestres da Humanidade: Sócrates, Buda, Confúcio e Jesus (Jaspers, 2003). O silêncio interior, na qualidade de símbolo pedagógico e de sabedoria, foi sempre levado muito a sério pelas figuras iluminantes atrás citadas, não esquecendo, entre outras, as do "Magister Ludi" (Joseph Knecht - cujo significado é aquele que serve) de Castália, do Jogo das Pérolas de Vidro de Hermann Hess (1987), e do barqueiro Vasudeva, do Sidharta de Hermann Hess (1982), que possuía a virtude de saber ouvir como poucos (1992: 110). No entanto, constata-se que este tipo de silêncio é secundarizado, senão mesmo esquecido, na relação educativa atual pelo facto de esta, sob o domínio da palavra, o considerar ora filho de um deus menor, ora património do "sagrado claustral". O silêncio é necessário ao ato de pensar que se pretende reflexivo e não há educação que resista à falta deste tipo de pensamento crítico pela razão de que o ato de pensar dá-se mal fora de um tempo que lhe seja propício, ou seja, inscreve-se num tempo longo. A educação contemporânea negligenciando a dimensão pedagógica do silêncio, erradicando, por exemplo, a meditação e mesmo a contemplação, coloca em causa não somente a formação do educando como também não ajuda a que ele encontre o seu caminho, enfim, o seu destino na linha de Os Anos de Aprendizagem de Wilhelm Meister de Goethe (1795). O educador, e muito especialmente um Mestre, deve saber qual o momento oportuno de fazer silêncio e de falar. $\mathrm{O}$ ato de escutar é o momento do comprometimento, do empenhamento em que o educador, ou Mestre, se dá conta de que há sempre um terceiro que acompanha, presente no diálogo - é o silêncio que escuta e, quando respeitado, é o próprio diálogo que ganha em profundidade e em plenitude: "Finalmente, a presença do silêncio no seio do diálogo significa que a alteridade e a reciprocidade das consciências são e permanecem correlativas e complementares" (Rassam, 1980: 139). É portanto esta mensagem que uma pedagogia do silêncio deve potencializar mediante quatro aspetos salientados por Angelo Caranfa 
que resumimos do seguinte modo: o pensamento crítico carece, para frutificar, de um silêncio interior inspirador e este só se consegue mediante um tempo de solidão, de esforço, de prática medidativa e silenciosa, de empatia, de confiança, de sinceridade, de amor e de aprendizagem com o fracasso. A tudo isto se acrescenta a escrita e o pensar como modos de interpelar o sentido do eu, do mundo, assim como o encontro do Outro que tem, como consequência, que o sujeito não seja egoísta e egóico, mas se esforce por viver uma alteridade plena e liberta da ilusão dos seus pequenos poderes (2006: 98-101). Daí que seja compreensível que toda uma pedagogia do silêncio se imponha porquanto

a ideia de que aprender ou ensinar é permanecer na solidão; na solidão aprendemos a sentir e pensar belos pensamentos sozinhos, e a própria professora deve ser contemplativa, movida não por explicações infindáveis sobre explicações, mas esforçando-se por permanecer em silêncio diante da dimensão inexplicável da experiência humana e do mundo (Caranfa , 2006: 101).

Assim, uma pedagogia do silêncio não pode deixar de ser, a seu modo, uma pedagogia do sentido (Torralba, 2014), ou seja, que ensine o sentido do(s) silêncio(s) (do calar prudente e sensato e não do silenciamento), do escutar e do falar (Fiumara, 2016; Torralba, 2010). Por isso, importa compreender não só os méritos espirituais e pedagógicos do silêncio como também os da palavra porquanto aquele que escuta ouve sempre uma palavra que se espera que seja reflexiva ou justa. Deste modo, não há lugar para o confronto entre palavra e silêncio como diz Huey-li :

O silêncio é um fenómeno cultural complexo e complicado. Embora seja habitual ver o silêncio como o oposto da fala [palavra], faz-se também notar que o silêncio, de facto, complementa a fala [palavra]. (...) Silêncio e fala são as fundações inseparáveis da comunicação humana. Contudo a dicotomização do silêncio e fala desencaminha-nos desvalorizando o silêncio e privilegiando a fala. Em vez disto, reclamo a necessidade de desmantelar esta falsa dicotomia e o desenvolvimento de uma compreensão pedagógica do silêncio $(2001:$ 157, 163).

Do exposto, antevemos que se a palavra escutar o silêncio e este igualmente a ouvir, abrir-se-ão possibilidades, na base de uma esperança razoável, de uma pedagogia do silêncio contribuir para que o silêncio interior, assim como a Palavra que dele brota, sejam, por fim, escutados e seguidos. 


\section{Conclusão}

Tratar o tema do silêncio interior e da sua pedagogia deveria ser uma das preocupações principais das filosofias da existência e da educação, e das pedagogias que de algum modo as acompanham, mas tal não acontece como seria, aliás, expectável. Isto contribui naturalmente não apenas para o seu enfraquecimento epistémico e, consequentemente, alcance reflexivo, espelhado por aquilo que Daniel Hameline denomina de "lugares comuns" no pensamento sobre a educação (2000: 23-24). Quando falamos da importância e da necessidade de uma pedagogia do silêncio não é nossa intenção escrever um manifesto anti-comunicação, uma espécie de reflexão maniqueísta em que o Silêncio de opõe à Palavra no seu sentido iniciático. Daí que façamos nossas as palavras de David Le Breton:

Certamente, o meu elogio do silêncio é também um elogio da palavra! A matéria primeira da ligação social, da amizade, do amor, é a troca de palavras, mas num mútuo reconhecimento do direito a calar-se em consideração do rosto do outro. O silêncio é um lugar essencial de comunicação entre amantes ou entre amigos. Poder calar-se conjuntamente é um grande sinal de cumplicidade (2016: 12).

Por isso é que o nosso trabalho procurou refletir sobre o modo como o silêncio interior pode conduzir o sujeito a atribuir maior valor e importância àquilo que diz e como o diz, ou seja, à palavra interior e reflexiva e, por maioria de razão, à Palavra iniciática. Dito de outra maneira, se, por um lado, não fazemos apologia de um tipo de silêncio "gangrenático" que mata ou fere a Palavra de morte, por outro lado, parece não haver Palavra que entusiasme, ou que prevaleça, se ela não se alimenta do silêncio vivo, do silêncio interior, entendido este como aquele que inquieta, que conduz à reflexão e, em última instância, à meditação. Parafraseando Hermann Hesse, no seu Siddhartha, possamos dizer que "Escrever é bom, pensar é melhor. Inteligência é bom, paciência é melhor" (1982: 71), mas o silêncio interior e a meditação são igualmente melhores. E assim devemos, também nós, deixar-nos tentar pelo cântico do silêncio que nos sussurra a partir da sua vasta imensidão das esferas a fim que o advento do Homo Silens aconteça! (Karahasan, 2015: 729-738).

\section{Notas}

1 O presente artigo prolonga algumas das preocupações já desenvolvidas na obra do autor intitulada Silêncio. Iniciação e Transformação. O autor agradece aos Professores Cecília Sanchez Teixeira (Universidade de São Paulo - USP - Brasil) e João Bento Mesquita (Investigador independente) o seu muito pertinente trabalho de revisão. Este trabalho é financiado pelo ClEd - Centro de Investigação em Educação, projetos UID/CED/01661/2019, Instituto de Educação, Universidade do Minho, através de fundos nacionais da FCT/MCTES-PT.

2 Permitimo-nos chamar a atenção para o artigo de Sebastian Painadath (2015). La Fuerza Transformadora del Silencio Contemplativo: 703-714. 
3 Nesta linha, parece-nos também que Merleau-Ponty, na sua obra Le visible et l'invisible (1964), aponta a importância de o filósofo escutar e relacionar-se com um silêncio que ouve em si mesmo, já que o silêncio o coloca em diálogo com o ser do Ser (2001: 166 e 169).

\section{Referências}

Araújo, A. F. (2018). Silêncio. Iniciação e Transformação. Maia: Instituto Universitário da Maia (ISMAI).

Baldini, M. (1986). Le parole del silenzio. Cinisello Balsamo (Milano): Edizioni Paoline.

Breton, Ph, \& Le Breton, D. (2009). Le silence et la parole contre les excès de la communication. Strasbourg: Arcanes.

Bruneau, Th. J. (1973). Communicative Silences: forms and Functions. Journal of Communication, 23, (1), 17-46.

Caranfa, A. (2004). Silence as the Foundation of Learning. Educational Theory, 54, (2), 211-230.

Caranfa, A. (2006). Voices of Silence in Pedagogy. Art, Writing and Self-Encounter. Journal of Philosophy of education, 40, (1), 85-103.

Cingolani, S. (2012). Per una Storia del Silenzio. Milano. Mursia.

Corbin, A. (2006). Histoire du silence. De la Renaissance à nos jours. Paris: Albin Michel.

Dauenhauer, B. P. (1980). Silence. The Phenomenon and Its Ontological Significance. Bloomington. Indiana University Press.

Eliade, M. (2001). Initiation, rites, sociétés secrètes. Paris: Gallimard.

Eliade, M. (2008). Mythes, rêves et mystères. Paris: Gallimard.

Ephratt, M. (2008). The functions of silence. Journal of Pragmatics, 40, 1909-1938.

Fermor, P. L. (2018). Tempo de Silêncio. Trad. de Alda Rodrigues. Lisboa: Tinta-da-china.

Forrest, M. (2013). Practising Silence in Teaching. Journal of Philosophy of Education, 47, (4), 605-622.

Gennari, M. (1997). Storia della Bildung. Formazione dell'uomo e storia della cultura in Germania e nella Mitteleuropa. Brescia: La Scuola.

Gennari, M. (2005). Filosofia della formazione dell'uomo. Milano: Bompiani

Glenn, C. (2004). Unspoken. A Rhetoric of Silence. Carbondale: Southern Illinois University Press.

Hameline, D. (2000). Courants et contre-courants dans la pédagogie. Issy-les-Molineaux: ESF éditeur.

Han, B-C. (2012). La sociedad del cansancio. Trad. de Arantzazu Saratxaga Arregi. Barcelona: Herder.

Hastedt, H. (2012). Was ist Bildung? Eine Textantalogie. Stuttgart: Reclam.

Heidegger, M. (2000). Serenidade. Trad. e Maria Madalena Andrade e de Olga Santos. Lisboa: Instituto Piaget.

Hesse, Hermann (1982). Siddharta. Trad. de Fernanda Pinto Rodrigues. ( $2^{a}$ ed). Lisboa: Editorial Minerva. Hesse, H. (1987). Das Glasperlenspiel. Frankfurt am Main: Suhrkamp Verlag.

Jaspers, K. (2003). Os Mestres da Humanidade. Sócrates, Buda, Confúcio, Jesus. Trad. de Jorge Telles de Menezes. Coimbra: Almedina. 
Jaworski, A. (1993). The power of silence: social and pragmatic perspectives. Newbury Park: Sage. Jaworski, A. (1997). Silence. Interdisciplinary Perspectives. Berlin - New York : Mouton de Gruyter. Jensen, J. V. (1973). Communicative Functions of Silence. ETC: A Review of General Semantics, 30, (3), 249-257.

Johannesen, R. L. (1974). The functions of silence: a plea for communication research. Western Speech, 38, (1), 25-35.

Kurzon, D. (1998). Discourse of Silence. Amesterdam/Philadelphia: John Benjamins Publishing Company.

Kurzon, D. (2007). Toward a typology of silence. Jornal of Pragmatics, 39, 1673-1688.

Le Breton, D. (1999). Do silêncio. Trad. de Luis M. Couceiro Feio. Lisboa: Instituto Piaget.

Li-Huey (2001). Silences and Silencing Silences. The Yearbook of Philosophy of Education, 157-165.

Mendonça, J. T. (2012). Nenhum Caminho será Longo. Para uma Teologia da Amizade. Prior Velho: Paulinas.

Mendonça, J. T. (2015). Somos analfabetos do silêncio. Revista Expresso (12/06), n 2224, 90.

Merleau-Ponty, M. (2001). Le visible et l'invisible. Paris: Gallimard.

Merton, T. (1960). A Vida Silenciosa. Petrópolis: Editora Vozes.

Noacco, C. (2017). La Force du Silence. Petites notes sur le bruissement du monde. Paris: Transbóreal.

Painadath, S. (2015). La Fuerza Transformadora del Silencio Contemplativo. Concilium. Revista Internacional de Teologia, 363, 703-714.

Pessoa, F. (2014). Fernando Pessoa. Poemas escolhidos de Alberto Caeiro. Lisboa: Assírio \& Alvim.

Picard, M. (1954). Le monde du silence. Trad. de J.-J. Anstet. Paris : PUF.

Rassam J. (1980). Le Silence comme Introduction à la Métaphysique. Toulouse : Publications de l'Université de Toulouse - le Mirail (Série A - Tome 44).

Reboul, O. (1992). Les valeurs de l'éducation. Paris: PUF.

Reboul, O. (2000). A Filosofia da Educação. Trad. de António Rocha e de Artur Morão. Lisboa: Edições 70.

Rosa, H. (2018). Résonance. Une sociologie de la relation au monde. Trad. de Sacha Zillberfarb avec la collab. de Sarah Raquillet. Paris : La Découverte.

Sarah, R. ; Diat, N. (2017). A Força do Silêncio. Contra a ditadura do barulho. Trad. de Maria João Carmona. Cascais: Lucerna.

Saville-Troike, M. (1985). The Place of Silence in an Integrated Theory of Communication. In Tannen, D.; Saville-Troike, M. (edited by). Perspectives on Silence. (pp. 3-18). Norwood, New Jersey: Ablex Publishing Corporation.

Scott, R. L. (1972). Rhetoric and Silence. Western Speech, 36, (3), 146-158.

Siegel, H. (Ed.) (2009). The Oxford handbook of philosophy of education. Oxford: Oxford University Press.

Sola, G. (2003). Umbildung. La «transformazione» nella formazione dell'uomo. Milano: Bompiani. 
Torralba Roselló, F. (2001). El silencio: un reto educativo. Trad. de Carme del Blanco Barnusell. Madrid: PPC.

Torralba Roselló, F. (2014). Pedagogía del Sentido. (2ª ed). Madrid: PPC.

Zenbylas, M. (2004). The Sound of Silence in Pedagogy. Educational Theory, 54, (2), 193-210.

Zimmermann, A. C. \& Morgan, W. J. ((2016). A Time for Silence? Its Possibilities for Dialogue and for Reflective Learning. Studies in Philosophy and Education, 35, (4), 399-413.

\section{Alberto Filipe Araújo \\ Professor Catedrático do Instituto de Educação da Universidade do Minho (Braga - Portugal) Membro integrado do Centro de Investigação em Educação (CIEd) do Instituto de Educação da Universidade do Minho. \\ Email: afaraujo@ie.uminho.pt ORCID: http://orcid.org/0000-0002-4693-8681}

Correspondência Alberto Filipe Araújo Universidade do Minho. Instituto de Educação. Campus de Gualtar, 4710057 Braga - Portugal.

Data de submissão: Março 2019

Data de avaliação: Maio 2019

Data de publicação: Dezembro 2019 